\title{
Review of the Theory and Application of Big Data in Urban Spatial Optimization
}

\author{
Zijun Ye \\ College of Urban and Environment Sciences, Peking University, Haidian District, Beijing, China \\ Email:Zijun.y@pku.edu.cn
}

\begin{abstract}
This article applies the literature review method to sort out and summarize the results on the theory and the application of big data in urban space optimization research. It founds that the domestic research on spatial optimization started relatively late, mainly in terms of the optimization of the number of land use structures and the division of land use. But in the context of urban renewal, research on spatial optimization strategies is still rare. Exploring spatial pattern optimization from the perspective of sustainable renewal will provide new perspectives and new methods for China's stock space optimization. Scholars from China or abroad have used big data to conduct more research and discussion on related decisions on urban problem governance. In terms of land use optimization, big data can also overcome these limitations to a large extent, especially in the study of urban expansion boundaries, land use function layout, function facility layout and other aspects.
\end{abstract}

Keywords: urban space optimization, big data, theory, application

\section{INTRODUCTION}

"Urban space" mainly refers to the spatial structure and spatial form of each component of the city. The urban spatial structure shows the distribution characteristics and combination relationship of various material elements in the city within the spatial scope, and it reflects the internal mechanism of the city. The urban space form is a concrete reflection of the urban space structure. The urban space structure determines the kind of urban space form [1]. The urban spatial structure has five major elements: nodes, gradients, channels, networks, and circle-and-surfaces. It has five flow patterns: population flow, material flow, technology flow, information flow, and capital flow [2]. "Optimization" refers to improving on the original basis in order to make someone or something better. Generally speaking, the purpose of optimization research is to choose the best solution from the alternatives, and to provide a solution to the problem of how to minimize the resource consumption while achieving the ultimate comprehensive benefit. The optimization of urban space can be understood as the dynamic change process of organic coordination between urban physical space, economic space, natural space and social space with the goal of full, reasonable and intensive use of urban space by human beings. From the perspective of system theory and space, the optimization of urban space is to achieve harmony within the city and co-existence with the outside, and to achieve the overall optimization of various element systems in the city in different geographical spaces [3]. Optimizing the space for urban development, emphasizes the coordination of urban internal subsystems, including the coordinated development of industrial structure, urban spatial structure, urban infrastructure construction, urban environmental resources development and protection, and various administrative relations. It also emphasizes the coordination between the city as a whole of interest and different external interest subjects, including how to establish and improve urban planning mechanisms and urban development cooperation mechanisms.

\section{RESEARCH ON THEORIES OF URBAN SPACE OPTIMIZATION}

\subsection{Theories of Urban Space Optimization}

\subsubsection{Location theory}

Location theory is the theory about the spatial distribution of land use and their interrelationships in space activities. Throughout the domestic and foreign related location theories, there are four types including Dunn's agricultural location theory, Weber's industrial location theory, Christaller's central location theory, and Liao's market location theory. Different geographical locations cause different lands to have different physical, chemical, and biological characteristics. Different distances from central cities, main roads, transportation hubs, or business centres have different economic values or uses. This is the regional nature of the land or the location of the land. When planning the layout of land, we must follow the location theory, rationally optimize the space use structure of the land, while maximizing the economic, social and environmental benefits of the land. 


\subsubsection{Systems engineering theory}

System Engineering is an applied branch of science in systems science. It is based on the whole system and takes the overall situation into consideration. The correlation between the optimization of the structure and layout of urban construction land and the theory of systems engineering includes the following aspects. First, In the urban construction land system, the change in the role of one factor will be magnified, resulting in changes in other factors and even the entire system. Second, structure determines function. The rationalization of urban construction land structure can produce structural effects, which can enhance and improve the function and efficiency of the entire system. Therefore, it is necessary to strengthen the control of the layout of various types of construction land in cities based on the principles of system theory, so that urban construction land becomes an organic whole, and its internal relevance, hierarchical structure and dynamic balance must be fully explored.

\subsubsection{Spatial structure theory}

Spatial structure refers to the degree of spatial agglomeration and agglomeration forms formed by the interaction of various economic activities within a region. There are four widely used spatial structure theories in the current spatial layout, including the central place theory, the "point-axis" system theory, the growth triangle theory, and the dual-core structure model. The spatial optimal layout of land use means that the land can be reasonably arranged in time and optimally implemented in space so that the land can exert its best economic, social and ecological benefits. Restructuring the spatial structure of land to make it more efficient in allocating resources is one of the first tasks of the spatial layout of land use planning in the new period.

\subsection{Research on the Optimization of Land Development Space}

Land development space optimization is also called land use space optimization configuration. It has specific planning goals. With the help of certain technical means, it optimizes the structure and direction of land use in the region on the time scale and space scale. The optimization mainly reflects in the rational combination and layout of the land use types in terms of quantity and space. The optimization results are mainly manifested in multiobjective, multi-level and multi-category land use space allocation schemes [4]. At present, the research on the optimal allocation of land use space focuses on the realization of comprehensive social, economic, and ecological benefits and the optimization of the structure of the number of land uses. It is less important to analyse the spatial layout characteristics of land development and the importance of coordinated regional development from the perspective of the whole region. As one of the important contents of optimal land use allocation, land development space optimization is helpful for identifying the characteristics of regional land use from a spatial perspective, providing scientific basis and support for improving land use efficiency, maximizing the use of land use functions, and coordinating regional development.

Theoretical research on the optimization of land development space abroad can be traced back to the early 19th century. Since the 1970s, issues such as population, resources, environment, and socio-economic development have become increasingly prominent. Land-use planning no longer stays in traditional constructive planning, but enters into the stage of substantive purpose of controlling land-use change and sustainable development. During this period, control theories and system optimization methods such as non-linear planning and linear programming penetrated into the research of land use space optimization, and provided effective technical support for land use planning and decision-making on the method model. The combination of 3S technology and mathematical models, effectively promoted the development of research on optimal allocation of land resources.

The research on the optimization of land development space in China began in the 1980s, and it started relatively late, mainly in terms of the optimization of the number of land use structures and the division of land use. From the perspective of research fields, research on land development space optimization mainly focuses on urban planning and overall land use planning. From the research scale, the research on the optimization of land development space at the meso and micro scales, such as city and county administrative districts, is mainly carried out in terms of land use quantity and structure optimization, land use zoning, etc., while the optimization of large-scale land development space such as cluster areas is mainly represented by the main functional zoning, comprehensive land use zoning, and land use strategic zoning. In terms of research data, remote sensing data and GIS technology are mainly used. National and large-scale regional research mainly uses city and county-level administrative districts as basic research units. Research areas below county-level are usually township administrative districts or land maps. The research area will be rasterized and the research on land use spatial configuration will be gradually directed to a smallscale direction. Among them, the research on the optimization of land use space in urban areas focuses on the development and utilization of urban construction land and the study of space allocation.

\section{RESEARCH ON APPLICATIONS OF BIG DATA IN URBAN SPATIAL OPTIMIZATION}

\subsection{Application of Big Data in Urban Studies}

In the process of urbanization, "urban diseases" and other urban problems have concentratedly erupted, bringing 
severe challenges to urban governance. Relying on big data as the core of new-generation information technology to build smart cities can bring new technological and effective methods to the management of "urban diseases" [5]. From the perspective of data status and data processing technology, big data refers to the massive, high growth rate and diversified information assets that require new processing models to have stronger decision-making power, insight and process optimization capabilities. Diversity, high speed, authenticity and other characteristics are new production factors, resources and wealth, and core competitiveness. Through simulation, correlation, fusion, analysis and other technologies, it can process complicated multi-source heterogeneous data into effective information with decision-making value, help government forecast and scientific decision-making, support scientific urban governance, personalized and accurate public services. From the perspective of thinking mode, big data thinking emphasizes the analysis of overall data related to things, rather than taking a small number of data samples; focusing on the confounding and related relationships of things, rather than exploring the causal relationship between things. In the past, considering urban issues was often based on localities and formed many information islands. Big data thinking is to allow urban decision makers to plan urban development with a systematic, three-dimensional, multidimensional and matrix thinking.

Scholars of China and abroad have used big data to conduct more research and discussion on relevant decision-making related to urban problem governance, mainly based on the social network data (user geographic location, activity information, emotional text, etc.), mobile phone call data, smart traffic swipe cards and the mining and analysis of city monitoring equipment data. The inter-city network activity is studied to determine the inter-city inter-connectivity and hierarchy [6], the simulation of urban resident travel patterns and population movement changes to guide more reasonable traffic planning and land use adjustment [7], combining the residents' emotions and activities to divide the urban centre area [8], and analysing major urban events or activities to study the social space structure with different population characteristics [9].

\subsection{Application of Big Data in Land Use Optimization}

Land use and functional layout are the most basic and important contents in planning, but traditional research often suffers from data update speed, quality reliability, and data accessibility. Big data can overcome these limitations to a large extent, especially it has accumulated rich experience in the research of urban expansion boundary [10], land use functional layout [11], and functional facility layout [12]. Long Ye et al. [13] used road network data as a unit, combined with POI data to identify built-up areas through a constrained cellular automaton, and then subdivided the use function, degree of mixing, and openness of the plot vertically. Gu [14] used the kernel density clustering method to analyse the POI and combined the mining of taxi trajectory data to identify urban functional areas. The results show that this method is feasible for urban functional identification. Long et al. [15] identified functional areas of Beijing based on POI and bus credit card data. Chen et al. [16] explored the inherent laws of urban development by selecting typical rapid urbanization areas for integrated modelling of urban expansion, building a more accurate model for urban expansion, designing a rational and orderly land use structure, and then planning and guiding rationally Land development. Huang et al. [17] explored the working ideas and potential applications of land use space optimization under the big data model by analysing the effect of current big data technology on land use optimization.

\section{CONCLUSION}

The domestic research on space optimization started relatively late, mainly in terms of the optimization of the number of land use structures and the division of land use. Among them, the research on the optimization of land use space in urban areas focuses on the development and utilization of urban construction land and the study of space allocation. But in the context of urban renewal, research on spatial optimization strategies is still rare. Exploring spatial pattern optimization from the perspective of sustainable renewal will provide new perspectives and new methods for China's stock space optimization.

Scholars from China and abroad have used big data to conduct more research and discussion on relevant decisions related to the governance of urban issues, such as judging the internal connections and hierarchical systems of cities by studying network activities between cities. In terms of land use optimization, big data can also overcome these limitations to a large extent, especially in the study of urban expansion boundaries, land use function layout, function facility layout and other aspects. But at present, the research objects of big data are still relatively single, and most of them are transport research. Urban renewal is a complex and large-scale project that involves all aspects of urban development and residents' activities. Therefore, this study is helpful for the scientific formulation of big data's identification and solution strategies for urban complex problems.

\section{REFERENCES}

[1] S. Wan, et al. Urban Space Analysis[M]. Science Press, 2004.

[2] C. Gu, F. Zhen, J. Zhang. Agglomeration and Diffusion: a New Theory of Urban Spatial Structure [M]. Southeast University Press, 2000.

[3] Z. Han, J. Guo, P. Zhang. Shenyang Urban Space Optimization and Regulation Strategy[J]. Urban Studies, 2011, pp. 91-98. 
[11] T. Hu, J. Yang, X. Li, et al. Mapping urban land use by using landsat images and open social data[J]. Remote Sensing, 2016, pp. 151.

[12] P. Zhang, J. Zhou, T. Zhang. Quantifying and visualizing jobs-housing balance with big data: A case study of Shanghai[J]. Cities, 2017, 66, pp. 11-22.

[13] P. J. C. Garcia, J. Gutierrez, C. Minguez. Identification of tourist hot spots based on social networks: A comparative analysis of European metropolises using photo-sharing services and GIS[J]. Applied Geography, 2015, 63, pp. 408-417.

[14] Y. Long, K. Wu, J. Wang, et al. Mockups: New Paradigms for Urban and Regional Studies[J]. Urban Planning Forum, 2014, pp. 52-60.

[15] Y. Gu, L. Jiao, T. Dong, et al. City Function Identification and Interaction Analysis Based on Multisource Data $[\mathrm{J}]$. Journal of Wuhan University (Information Science Edition), 2018, pp. 1-9.

[16] W. Chen, Z. Zhang, X. He. Refined Research on Urban Expansion in the Era of Big Data[J]. Urban Studies, 2017, pp. 71-76.

[17] H. Huang, Q. Li. 大 Opportunities, data sources and potential applications of land use optimization in the data age [J]. China Land Science, 2017, pp. 74-82.
[10] D. Yang. The fusion of big data and complexity theory in the study of urban residents' spatial activities [J]. Urban Planning Forum, 2017, pp. 31-36. 